Recebido em 02/05/10/2018. Aprovado em 20/09/2018. Avaliado pelo sistema cablebdindpeer reiew Publicado conforme normas da ABNT. http://dx.doi.org/10.22279/navus.2019.v9n3.p07-19.769

\title{
Indicadores de gestão do ensino técnico federal e sua correlação com eficiência acadêmica: uma análise da relação entre o desempenho discente e os investimentos ocorridos com a política pública de expansão dos institutos federais da região Nordeste entre 2012 e 2016
}

\author{
Marília Cristyne Souto Galvão Barros Matsumoto Mestranda em Administração Pública. Universidade Federal de Alagoas (UFAL), \\ Brasil - marilia.matsumoto02@gmail.com \\ Sheila Andréa Silva de Albuquerque Mestranda em Administração Pública. Universidade Federal de Alagoas (UFAL), \\ Brasil - sheilinhandrea@gmail.com \\ Luciana Peixoto Santa Rita Doutora em Administração. Universidade Federal de Alagoas (UFAL), Brasil - \\ Isantarita@hotmail.com \\ Ibsen Mateus Bittencourt Santana Pinto Doutor em Administração de Empresas. Universidade Federal de Alagoas (UFAL), \\ Brasil - ibsen.ead@gmail.com
}

\section{RESUMO}

A criação dos Institutos Federais de Educação, Ciência e Tecnologia (IFEs), enquanto política pública de expansão do ensino técnico-tecnológico ensejou um aumento exponencial de recursos aplicados nos mesmos. Para acompanhamento do desempenho e avaliação dos resultados quanto à destinação de recursos materiais e humanos, o Tribunal de Contas da União (TCU) estabeleceu indicadores acadêmicos que expressam o resultado da ampliação da oferta e a melhoria da eficiência e da eficácia das instituições federais de educação profissional. 0 objetivo deste artigo é analisar, nos Institutos Federais da Região Nordeste entre os anos de 2012 e 2016, a correlação entre a Taxa de Eficiência Acadêmica dos Concluintes - indicador de qualidade que mede a capacidade de alcançar êxito entre os alunos que finalizam - e os demais indicadores de gestão estabelecidos, desde 2005, pelo TCU, para as Instituições da Rede Federal de Educação Profissional e Tecnológica - EPCT. Quanto à metodologia, foi empregada a análise quali-quantitativa para melhor atender ao objetivo da pesquisa, que enseja a apreciação de dados numéricos mensuráveis, sem prejuízo da análise dos fatores motivacionais e interpretativos. Os resultados mostraram que não existe relação entre o indicador de qualidade Taxa de Eficiência Acadêmica de Concluintes e os indicadores de gestão estabelecidos pelo TCU na amostra analisada.

Palavras-chaves: Indicadores. Políticas Públicas. Eficiência Acadêmica. Educação Pública Técnico-Tecnológica. Rede Federal de Ensino.

\section{Management indicators of federal technical education and its correlation with academic efficiency: an analysis of the relationship between disciplinary performance and investments occurred with the public policy of expansion of the federal institutes of the Northeast region between 2012 and 2016}

\begin{abstract}
The creation of the Federal Institutes of Education, Science and Technology (IFEs), as a public policy for the expansion of technical and technological education, has led to an exponential increase in the resources applied to them. In order to monitor the performance and evaluation of results regarding the allocation of material and human resources, the Federal Audit Office (TCU) established academic indicators that express the results of the expansion of supply and improve the efficiency and effectiveness of federal institutes of professional education. The objective of this article is to analyze, in the Federal Institutes of the Northeast Region between the years of 2012 and 2016, the correlation between the Academic Efficiency Rate of the graduating students - quality indicator that measures the capacity to achieve success among the students that finish the courses - and the other management indicators established since 2005 by the TCU for the Institutions of the Federal Professional and Technological Education Network - EPCT. As for the methodology, the qualitative-quantitative analysis was used to better meet the research objective, which leads to the appreciation of measurable numerical data, without interfering with the analysis of motivational and interpretative factors. The results showed that there is no relation between the Quality Indicator of the Academic Efficiency of Graduating students and the management indicators established by the TCU in the sample analyzed.
\end{abstract}

Keywords: Indicators. Public policy. Academic Efficiency. Technical-Technological Public Education. Federal Network of Education. 


\section{INTRODUÇÃO}

A Constituição Federal de 1988 (CF/88) estabelece a educação como "um direito de todos e um dever do Estado e da família, promovida e incentivada com a colaboração da sociedade, visando ao pleno desenvolvimento da pessoa, seu preparo para o exercício da cidadania e sua qualificação para o trabalho" (BRASIL, 1988). Assim, o Estado, apesar de não ser o único encarregado pela execução da educação profissional e tecnológica, é o responsável tanto pela garantia de acesso a todos os cidadãos por meio da concepção de políticas públicas, bem como, pelo seu acompanhamento e controle. Essas políticas públicas educacionais, cabe mencionar, são ainda sujeitas à apreciação do legislativo e ao controle social, por serem dotadas de recursos orçamentários públicos.

Quanto à formulação de políticas públicas, temos que as demandas crescentes por uma formação que contemple ciência, tecnologia e trabalho, bem como atividades intelectuais e instrumentais, culminaram com a criação dos Institutos Federais de Educação, Ciência e Tecnologia através da Lei 11.892, publicada em 29/12/2008 (BRASIL, 2008). Na ocasião, a criação dos institutos e a política de expansão da rede técnicatecnológica de educação deveu-se à percepção de que esta, em termos universais, e no Brasil em particular, reveste-se cada vez mais de importância como elemento estratégico para a construção da cidadania e para uma melhor inserção de jovens e trabalhadores na sociedade contemporânea, plena de grandes transformações e marcadamente tecnológica (BRASIL, 2004). A partir de então, o número de unidades existentes quadruplicou e, como consequência, o orçamento destas aumentou exponencialmente, a fim de arcar com os valores de gastos por aluno, com os novos investimentos e com a contratação e qualificação de servidores técnicos-administrativos e docentes.

Apesar dos esforços dedicados a promover melhorias na qualidade da educação ofertada pelos Institutos Federais, o que pode ser observado no desempenho em exames nacionais e internacionais de conhecimento, bem como, por meio dos avanços graduais nos seus indicadores que demonstram maior investimento na permanência e eficácia, ainda permanece expressiva a taxa de reprovação e de abandono dos alunos, como é possível verificar nos dados anualmente divulgados pelo Instituto Nacional de Estudos e Pesquisas Educacionais Anísio Teixeira (Inep). Entretanto, como indica Souza et al. (2016, p. 23)

Essas vulnerabilidades não diminuem o mérito da política de expansão dos IFs no que tange à democratização do acesso à EP e ao ensino superior, principalmente, se considerarmos o avanço social que isso representa para cidades do interior do Brasil, cuja população tinha dificuldades de acesso a cursos de formação profissional e/ou superior de qualidade e público.

Dessa forma, com o intuito de aferir o nível de gestão das Institutos Federais de Educação, Ciência e Tecnologia no país, o TCU estabeleceu uma série de indicadores de qualidade e de gestão calculados mediante fórmulas específicas cujos valores variam conforme o desempenho institucional em cada item observado. Um desses indicadores é a Taxa de Eficiência Acadêmica de Concluintes (EAC), que objetiva medir a capacidade de alcançar êxito entre os alunos que finalizam os cursos. Este indicador relaciona todos os al unos que concluíram exitosamente seu curso no período (concluído ou integralizado), independentemente da época de seu ingresso; e, todos os que, de alguma forma, finalizaram seu curso, independentemente do êxito ou não, ou seja, busca examinar se os alunos concluíram sem ter evadido, desligado ou transferido.

Destarte, a partir dessas elucubrações, a questão que se busca responder com este artigo é: existe relação entre 0 aumento de gastos do governo, após o estabelecimento da política pública de expansão do ensino público federal, nos Institutos Federais da Região Nordeste entre os anos de 2012 e 2016, e a eficiência acadêmica, medida pelos indicadores estabelecidos Acórdão no 2.267/2005 - TCU/Plenário?

Para tanto, o objetivo do trabalho é analisar a correlação entre o Indicador Eficiência Acadêmica de Concluintes (EAC) e os indicadores de gestão estabelecidos pelo Tribunal de Contas da União. Em virtude de o universo compreender 39 institutos federais, optou-se por uma amostra, não probabilística, de 11 institutos federais localizados em uma mesma região do país.

Para análise foram escolhidos os institutos da região Nordeste por ser esta a região com o maior número de institutos e por ser a região onde a pesquisa foi desenvolvida. Optou-se por, adotando a mesma 
metodologia que o Inep, analisar institutos de uma mesma região a fim de minimizar os impactos sociais e culturais que poderiam interferir nos indicadores, pois, os indicadores educacionais atribuem valor estatístico à qualidade do ensino, atendo-se não somente ao desempenho dos alunos mas também ao contexto econômico e social em que as escolas estão inseridas (Inep). Como objetivos específicos, buscar-se-á sistematizar a evolução das políticas públicas voltadas para a educação profissional e tecnológica ao longo do tempo e evidenciar a importância das mesmas para a sociedade, bem como avaliar se a eficiência dos discentes, medidas pela EAC têm relação com a gestão financeira da instituição.

\section{FUNDAMENTAÇÃO TEÓRICA}

Inicialmente serão apresentados os conceitos de políticas públicas, bem como, propostas reflexões acerca das políticas públicas na educação federal com enfoque na expansão da Rede Federal de Educação Profissional, Científica e Tecnológica. Segue-se, ainda, com uma seção de discussão acerca dos indicadores de desempenho como instrumento de avaliação da política pública de expansão da Rede Federal de Educação Profissional, Científica e Tecnológica, especificando os indicadores estabelecidos pelo TCU, com destaque para 0 indicador Taxa de Desempenho.

\subsection{Políticas Públicas}

A CF/88 prevê diversos direitos resguardados aos cidadãos por meio de ações governamentais, como os direitos sociais de segurança, moradia, educação e saúde, cabendo ao Estado garantir um mínimo de dignidade a todo cidadão (PALADINO, 2008). Entretanto, os recursos de que o Estado dispõe são limitados. Assim, a sistematização de como esses recursos serão aplicados na busca por uma meta coletiva consciente é o que pode-se definir como política pública.

Políticas públicas, conforme definição de Souza (2006, p. 20), é "campo do conhecimento que busca, ao mesmo tempo, "colocar o governo em ação" e/ou analisar essa ação (variável independente) e, quando necessário, propor mudanças no rumo ou curso dessas ações (variável dependente)", contudo, tão importante quanto discutir uma definição, é examinar a repercussão dessas ações governamentais na sociedade.

Resende $(2017$, p. 4$)$ indica que "a percepção de um problema social como problema político, e sua construção discursiva como tal, é fator primordial para que se considere a relevância do enfrentamento de dito problema", nesse sentido, a autora refere-se a uma das etapas do ciclo de políticas públicas que, conforme Araújo e Gazzola (2017, p. 28) "envolve: formação da agenda, formulação da política, processo de tomada de decisão, implementação da política, acompanhamento e monitoramento, avaliação, feedback, retroalimentação e aprendizagem."

A fase inicial, de formação da agenda começa com a decisão do que é prioritário para o poder público. A fase de formulação refere-se à apresentação de soluções ou alternativas e consolidação dos objetivos. No processo de tomada de decisão, as alternativas são avaliadas e se define quais serão os recursos, os prazos e o curso de ação adotado. Na implementação os recursos são alocados, as responsabilidades são delegadas e os planos de ação são individualizados. As demais etapas, são posteriores à prática da política pública e refere-se à análise do desempenho dos atores, do uso dos recursos, adequação dos objetivos e ações e os resultados propriamente ditos e até o nível de satisfação dos beneficiários (ARAÚj 0; GAZZOLA, 2017).

No Brasil, a expansão da educação profissional e tecnológica integra-se à agenda pública que prevêa presença do Estado na consolidação de políticas educacionais, assumindo a educação como direito e afirmação de um projeto societário que corrobore uma inclusão social emancipatória (BRASIL, 2010). 


\subsection{Políticas Públicas na Educação Federal - A expansão da Rede Federal de Educação Profissional,}

\section{Científica e Tecnológica}

A instituição de políticas públicas educacionais, enquanto ação do Estado nas relações sociais, é entendida como uma política pública social, que segundo Höfling $(2001$, p. 31) são as "voltadas para a redistribuição dos benefícios sociais visando a diminuição das desigualdades estruturais produzidas pelo desenvolvimento socioeconômico". Nesse sentido, cabe analisar a expansão da rede pública federal de ensino técnico-tecnológico ocorrida a partir da primeira década do século XXI, sob a égide do que fora proposto na ocasião e o seu alcance em uma década.

A perspectiva de política pública na criação dos institutos federais em 2008 amplia de forma significativa esse conceito, ou seja, não basta a garantia de que é pública por estar vinculada ao orçamento e aos recursos de origem pública, é indispensável, sobretudo, que assente-se em outros itens também obrigatórios, como o comprometimento com o todo social, como algo que funda a igualdade na diversidade (social, econômica, geográfica, cultural etc.); e ainda estar articulada a outras políticas (de trabalho e renda, de desenvolvimento setorial, ambiental, social e mesmo educacional) de modo a provocar impactos nesse universo (BRASIL, 2010).

Conforme informações disponibilizadas no site do MEC, de 1909 a 2002, foram construídas 140 escolas técnicas no país. Entretanto, entre 2003 e 2016, o Ministério da Educação concretizou a construção de mais de 500 novas unidades referentes ao plano de expansão da educação profissional, totalizando 644 campi em funcionamento, passando de 119 a 568 municípios atendidos pela Rede Federal de Educação Profissional, Científica e Tecnológica. Se, quantitativamente, a expansão ampliou o acesso à educação enquanto direito social, as indicações das finalidades e características, na lei de criação dos institutos em 2010, estabeleceu parâmetros de qualidade aos mesmos, expressão de um Estado gerencial que, desde a reforma do final do século XX busca, não só o cumprimento legal, como também eficiente, de seus atos.

Art. 60 Os Institutos Federais têm por finalidades e características:

I - ofertar educação profissional e tecnológica, em todos os seus níveis e modalidades, formando e qualificando cidadãos com vistas na atuação profissional nos diversos setores da economia, com ênfase no desenvolvimento socioeconômico local, regional e nacional; II - desenvolver a educação profissional e tecnológica como processo educativo e investigativo de geração e adaptação de soluções técnicas e tecnológicas às demandas sociais e peculiaridades regionais;

III - promover a integração e a verticalização da educação básica à educação profissional e educação superior, otimizando a infraestrutura física, os quadros de pessoal e os recursos de gestão:

IV - orientar sua oferta formativa em benefício da consolidação e fortalecimento dos arranjos produtivos, sociais e culturais locais, identificados com base no mapeamento das potencialidades de desenvolvimento socioeconômico e cultural no âmbito de atuação do Instituto Federal;

$V$ - constituir-se em centro de excelência na oferta do ensino de ciências, em geral, e de ciências aplicadas, em particular, estimulando o desenvolvimento de espírito crítico, voltado à investigação empírica;

$\mathrm{VI}$ - qualificar-se como centro de referência no apoio à oferta do ensino de ciências nas instituições públicas de ensino, oferecendo capacitação técnica e atualização pedagógica aos docentes das redes públicas de ensino;

VII - desenvolver programas de extensão e de divulgação científica e tecnológica;

VIII - realizar e estimular a pesquisa aplicada, a produção cultural, o empreendedorismo, o cooperativismo e o desenvolvimento científico e tecnológico;

IX - promover a produção, o desenvolvimento e a transferência de tecnologias sociais, notadamente as voltadas à preservação do meio ambiente. (BRASIL, 2008).

É relevante destacar, de toda sorte, que o fortalecimento da rede federal de ensino técnicotecnológico ocorreu em um momento que a economia brasileira estava em franco crescimento e, assim, apesar dos altos valores, os investimentos não significaram um grande impacto orçamentário para o país. Ainda assim, foi expressiva e inédita a quantidade de recursos empregados em uma única política pública, por esse motivo, não haviam no momento mecanismos de avaliação e controle suficientes para acompanhá-los. 
Considerando a importância das ações de governo na busca para a melhoria da qualidade da educação brasileira e no desenvolvimento social, e os vultosos valores envolvidos, faz-se necessário o estabelecimento de indicadores de desempenho que expressem o grau de alcance das metas e objetivos estabelecidos.

\subsection{Indicadores de Desempenho como instrumento de Avaliação da política pública de expansão da Rede Federal de Educação Profissional, Científica e Tecnológica}

Indicadores de desempenho são, conforme Bueno e Torkomian (2018, p. 99) "instrumentos de decisão gerencial e são entendidos como formas de representação quantificáveis, usados por uma organização para controlar e melhorar o desempenho de seus processos ao longo do tempo", são, portanto, ferramentas de gestão que fornecem informações essenciais para o processo de tomada de decisão, devendo ser facilmente mensuráveis, apresentar-se em uma linguagem acessível e servir a diferentes hierarquias de decisão.

Para Petri $(2005$, p. 39), os gestores devem "buscar formas de medir e de avaliar a eficiência, a eficácia, a efetividade, a qualidade, a produtividade, a inovação, a lucratividade, entre outras características". Portanto, os indicadores são utilizados como parâmetros qualificados e/ou quantificados que servem para detalhar em que medida os objetivos de um projeto foram alcançados. Os indicadores são marcas ou sinalizadores que buscam expressar e demonstrar a realidade sob uma forma que seja possível observar e obter dados mais concretos para melhorar a avaliação da instituição (COELHO, 2009).

A identificação dos resultados das ações por meio de medidas de desempenho se constitui no eixo de comunicação com a sociedade, o que faz dos indicadores elementos fundamentais para todo o ciclo de gestão das políticas públicas (BRASIL, 2010). Nessa perspectiva, as instituições públicas necessitam desenvolver processos gerenciais que auxiliem na avaliação de seu desempenho, contando para isso com os indicadores de desempenho que são instrumentos capazes de fornecer informações importantes para o processo de tomada de decisão.

Em instituições públicas, as ações dos gestores devem ser pautadas visando o interesse público, pois a utilização dos recursos públicos deve ser executada de forma transparente para a sociedade. Assim, o Estado deve fornecer à sociedade informações dos resultados financeiros e da qualidade dos serviços prestados. Todavia, de acordo com Soligo (2012) aferir indicadores nas ciências sociais é uma tarefa mais difícil do que nas ciências exatas, pois muito daquilo que se pretende medir são conceitos intangíveis. Kloot e Martin (2000) salientam ainda que o desempenho organizacional seria melhor mensurado se os indicadores de desempenho avaliassem, além do aspecto financeiro, outras dimensões como a satisfação do cliente, os processos internos de negócios, a inovação e a aprendizagem.

Nesse sentido, os indicadores do TCU suscitados neste artigo objetivam o estabelecimento de indicadores acadêmicos que expressem a melhoria da eficiência e da eficácia das instituições federais de educação profissional, especificamente, uma análise da relação entre o desempenho discente e os investimentos ocorridos nos Institutos Federais da Região Nordeste.

\subsection{Indicadores do TCU para avaliação dos Institutos Federais}

Conforme estabelecido na CF/88, o Tribunal de Contas da União (TCU) é um órgão de controle externo do governo federal que auxilia o Congresso Nacional a acompanhar a execução orçamentária e financeira do país contribuindo com o aperfeiçoamento da Administração Pública em benefício da sociedade. Esse acompanhamento, geralmente, é realizado por meio de auditorias que resultam em acórdãos com informações, avaliações e determinações.

Assim, o Acórdão no 2.267/2005 - TCU - Plenário, resultante da auditoria realizada no Programa de Educação Profissional (Proep), a cargo da Secretaria de Educação Profissional e Tecnológica (Setec) e das Instituições Federais de Educação Tecnológica (Ifets), trouxe como determinação a necessidade da integração de 11 (onze) indicadores às prestações de contas das instituições de ensino. Os indicadores definidos pelo TCU como obrigatórios nos relatórios de prestações de contas anuais das gestões dessas instituições foram: Relação 
Candidato/Vaga (RCV), Relação Ingressos/Alunos (RIM), Relação Concluintes/Alunos (RCM), Índice de Eficiência Acadêmica de Concluintes (EAC), Índice de Retenção do Fluxo Escolar (RFE), Relação Alunos/Docente em Tempo Integral (RAD), Índice de Titulação do Corpo Docente (TCD), Gastos Correntes por Aluno (GCA), Percentual de Gastos com Pessoal (GCP), Percentual de Gastos com Outros Custeios (GOC) e Percentual de Gastos com Investimentos (GCI) (BRASIL, 2005).

Quadro 1 - Descrição dos indicadores dos IFEs

\begin{tabular}{|c|c|c|}
\hline Indicadores & Descrição & Fórmula \\
\hline $\begin{array}{l}\text { Relação } \\
\text { Candidato/Vaga } \\
\text { (RCV) }\end{array}$ & $\begin{array}{l}\text { Inscrições: número de inscrições para vestibular e processos } \\
\text { seletivos. } \\
\text { Vagas Ofertadas: número de vagas ofertadas em editais de oferta } \\
\text { de vagas por meio de vestibular, processos seletivos e outras } \\
\text { formas de ingresso. }\end{array}$ & $\begin{array}{l}\text { Indicador }= \\
\text { inscrições/vagas } \\
\text { ofertadas }\end{array}$ \\
\hline $\begin{array}{l}\text { Relação } \\
\text { Ingressos/Alunos } \\
\text { (RIM) }\end{array}$ & $\begin{array}{l}\text { Alunos matriculados: corresponde ao total de matrículas no ano, } \\
\text { considerando o conceito de matrículas do Inep / CENSO. } \\
\text { Ingressos: número de alunos ingressos por meio de vestibular, } \\
\text { processos seletivos e outras formas de ingresso. }\end{array}$ & $\begin{array}{l}\text { Indicador }= \\
\text { (ingressos/alunos } \\
\text { matriculados) } \times 100\end{array}$ \\
\hline $\begin{array}{l}\text { Relação } \\
\text { Concluintes/Alun } \\
\text { os (RCM) }\end{array}$ & $\begin{array}{l}\text { Alunos matriculados: corresponde ao total de matrículas no ano, } \\
\text { considerando o conceito de matrículas do Inep / CENSO. } \\
\text { Concluinte: número de alunos que integralizaram os créditos e } \\
\text { estão aptos a colar grau. }\end{array}$ & $\begin{array}{l}\text { Indicador }= \\
\text { (concluintes/alunos } \\
\text { matriculados) } \times 100\end{array}$ \\
\hline $\begin{array}{l}\text { Índice de Eficiência } \\
\text { Acadêmica - } \\
\text { concluintes (EAC) }\end{array}$ & Quantifica a eficiência das Instituições. & $\begin{array}{l}\text { Índice }=(\Sigma \text { de } \\
\text { concluintes por } \\
\text { modalidade } / \Sigma \text { de } \\
\text { Ingressos ocorridos por } \\
\text { modalidade }) \times 100\end{array}$ \\
\hline $\begin{array}{l}\text { Índice de } \\
\text { Retenção do Fluxo } \\
\text { Escolar (RFE) }\end{array}$ & $\begin{array}{l}\text { Alunos matriculados: corresponde ao total de matrículas no ano, } \\
\text { considerando o conceito de matrículas do Inep / CENSO. } \\
\text { Reprovação + trancamento: número de alunos que trancaram o } \\
\text { curso ou foram reprovados (Retenção Escolar). }\end{array}$ & $\begin{array}{l}\text { Índice }=\text { (reprovação }+ \\
\text { trancamento/alunos } \\
\text { matriculados }) \times 100\end{array}$ \\
\hline $\begin{array}{l}\text { Relação Alunos / } \\
\text { Docente em } \\
\text { Tempo Integral } \\
\text { (RAD) }\end{array}$ & $\begin{array}{l}\text { Alunos matriculados: corresponde ao total de matrículas no ano, } \\
\text { considerando o conceito de matrículas do Inep / CENSO. } \\
\text { Docente em tempo integral: professor que presta atividades } \\
\text { acadêmicas exclusivamente em sala de aula, em regime de } \\
\text { trabalho de } 40 \text { horas semanais. Docentes em regime de trabalho } \\
\text { com menos de } 40 \text { horas semanais serão computados } \\
\text { proporcionalmente à carga horária. (Cada docente com } 40 \text { h de } \\
\text { trabalho conta como } 1 \text { e com } 20 \text { h de trabalho como } 0,5 \text { ). }\end{array}$ & $\begin{array}{l}\text { Indicador = alunos } \\
\text { matriculados/ } \\
\text { docentes em tempo } \\
\text { integral }\end{array}$ \\
\hline $\begin{array}{l}\text { Índice de } \\
\text { Titulação do } \\
\text { Corpo Docente } \\
\text { (TCD) }\end{array}$ & $\begin{array}{l}\text { Quantifica o índice de titulação do corpo docente - efetivo e } \\
\text { substitutos; a titulação do corpo docente é dividida em } 5 \text { sub- } \\
\text { grupos: Pós-Doutor, Doutor, Mestre, Especializado e Graduado. }\end{array}$ & $\begin{array}{l}\text { Índice }= \\
\mathrm{G}^{*} 1+\mathrm{E}^{*} 2+\mathrm{M}^{*} 3+\mathrm{D}^{*} 5+\mathrm{PD} \\
* 5 / \mathrm{G}+\mathrm{E}+\mathrm{M}+\mathrm{D}+\mathrm{PD} \\
\mathrm{G}=\mathrm{Graduado} \mathrm{E}=\text { Especial } \\
\text { izado; } \mathrm{M}=\text { Mestre; } \\
\mathrm{D}=\text { Doutor; } \mathrm{PD}=\text { Pós- } \\
\text { Doutor }\end{array}$ \\
\hline $\begin{array}{l}\text { Gastos Correntes } \\
\text { por Aluno (GCA) }\end{array}$ & $\begin{array}{l}\text { Gastos correntes: todos os gastos, exceto investimento, capital, } \\
\text { precatórios, inativos e pensionistas e divide-se pelo número de } \\
\text { matrículas do mesmo ano. } \\
\text { Alunos matriculados: corresponde ao total de matrículas no } \\
\text { mesmo ano, considerando o conceito de matrículas do Inep. }\end{array}$ & $\begin{array}{l}\text { Indicador }=\text { total de } \\
\text { gastos correntes } / \\
\text { Alunos matriculados }\end{array}$ \\
\hline
\end{tabular}




\begin{tabular}{|c|c|c|}
\hline $\begin{array}{l}\text { Percentual de } \\
\text { Gastos com } \\
\text { Pessoal (GCP) }\end{array}$ & $\begin{array}{l}\text { Gastos com Pessoal: Gastos com servidores ativos, inativos, } \\
\text { pensionistas, sentenças judiciais e precatórios. } \\
\text { Gastos totais: Gastos totais de todas as fontes e todos os grupos } \\
\text { de despesa. }\end{array}$ & $\begin{array}{l}\text { Indicador }=\text { (total de } \\
\text { gastos com } \\
\text { pessoal/Gastos totais) } \\
\text { x100 }\end{array}$ \\
\hline $\begin{array}{l}\text { Percentual de } \\
\text { Gastos com } \\
\text { Outros Custeios } \\
\text { (GOC) }\end{array}$ & $\begin{array}{l}\text { Gastos com Outros Custeios: gastos totais de outros custeios } \\
\text { menos (-) benefícios, investimentos e inversões financeiras } \\
\text { Gastos Totais: gastos totais de todas as fontes e todos os grupos } \\
\text { de despesa. }\end{array}$ & $\begin{array}{l}\text { Indicador }=\text { (total de } \\
\text { gastos outros } \\
\text { custeios/Gastos totais) } \mathrm{x} \\
100\end{array}$ \\
\hline $\begin{array}{l}\text { Percentual de } \\
\text { Gastos com } \\
\text { Investimentos } \\
(\mathrm{GCl})\end{array}$ & $\begin{array}{l}\text { Investimentos: despesa destinada ao planejamento e execução } \\
\text { de obras, inclusive as relacionadas à aquisição de imóveis } \\
\text { considerados necessários à realização de obras. } \\
\text { Inversões Financeiras: despesa com aquisição de imóveis ou bens } \\
\text { de capital já em utilização e também a aquisição de títulos } \\
\text { representativos do capital de empresas ou entidades de qualquer } \\
\text { espécie, já constituídas. } \\
\text { Gastos Totais: gastos totais de todas as fontes e todos os grupos } \\
\text { de despesa. }\end{array}$ & $\begin{array}{l}\text { Indicador = total de } \\
\text { gastos com } \\
\text { Investimentose } \\
\text { inversões financeiras/ } \\
\text { gastos totais. }\end{array}$ \\
\hline
\end{tabular}

Fonte: Brasil (2005).

O mesmo documento destacou a conveniência de se implementar medidas corretivas no sistema de educação profissional e tecnológica, entre as quais o desenvolvimento de indicadores de gestão para as IFETS, bem como, afirmou que a definição desses indicadores deve permitir uma melhor avaliação da eficácia e da efetividade das políticas públicas de educação profissional executadas pelas Instituições de Educação Tecnológica (BRASIL, 2005).

O Acórdão n-2.267/2005 - TCU/Plenário ressaltava a necessidade de se buscar a coleta de dados para produção dos indicadores, de forma eletrônica, para todas as instituições da rede e de se estimular a coleta de dados socioeconômicos de todos os alunos para o cálculo do indicador de renda per capita dos alunos matriculados (BRASIL, 2005). Já o Acórdão no 2.508/2011 - TCU - 1a Câmara, chama a atenção para a necessidade de se buscar a avaliação da instituição como um todo, não mais através de estudos de caso, tendo em vista que os institutos federais já haviam sido criados e a Setec/MEC precisaria acompanhar a eficiência e eficácia das ações dos programas (BRASIL, 2011).

Para padronizar a geração dos indicadores, a Setec/MEC, desde o exercício de 2012, centralizou a extração de dados e a construção de tabelas com os indicadores, que são encaminhadas para as Instituições da Rede Federal. Dessa maneira, os relatórios de indicadores são gerados de forma padronizada e automatizada, pela extração centralizada no MEC - a partir de dados brutos dos sistemas SISTEC, SIAPE e SIAFI, sistemas oficiais de registro de matrículas, de gestão de pessoas e movimentação financeira - e posteriormente, validados com as próprias instituições (BRASIL, 2014).

\subsection{Taxa de Eficiência Acadêmica}

O indicador Taxa de Eficiência Acadêmica dos Concluintes (EAC), estabelecido no Acórdão no 2.267/2005-TCU/Plenário, mede a capacidade de alcançar êxito entre os alunos que finalizam. 0 cálculo proposto previa calcular este indicador pela relação entre todos os alunos que concluíram seu curso no período, independentemente da época de seu ingresso; e, todos os que "deveriam concluir" neste período (BRASIL, 2005).

Para adequar à metodologia do Sistema Nacional de Informações da Educação Profissional e Tecnológica (Sistec) baseada no conceito de ciclo de matrícula, este indicador passou a ser a relação entre todos os alunos que concluíram exitosamente seu curso no período, independentemente da época de seu ingresso; e, todos os que, de alguma forma, finalizaram seu curso, independentemente do êxito ou não. 
Quanto à metodologia de cálculo, para os registros dos concluintes são consideradas todas as matrículas que tiveram alteração de status para Concluído ou Integralizado nos meses de referência do intervalo de análise. Com relação aos registros dos finalizados são consideradas todas as matrículas que tiveram alteração de status para Concluído, Integralizado, Evadido, Desligado ou Transferido Externo nos meses de referência do intervalo de análise.

Esse indicador, especificamente, é de grande relevância pois expressa o resultado de todo o investimento na rede federal de ensino. É a culminância do trabalho realizado, pois, se o discente concluir exitosamente, todos os recursos gastos com ele terão retorno à sociedade na forma de um cidadão plenamente formado.

\section{ANÁLISE DOS RESULTADOS}

Apreciando os dados fornecidos pelos relatórios de gestão das instituições selecionadas como amostra, no período analisado de 2012 a 2016, foi possível comparar os valores do Gasto Corrente por Aluno (GCA) em série histórica.

Gráfico 1 - Gasto Corrente por Aluno (GCA) das instituições analisadas no período de 2012 a 2016 $\mathrm{R} \$ 25.000,00$

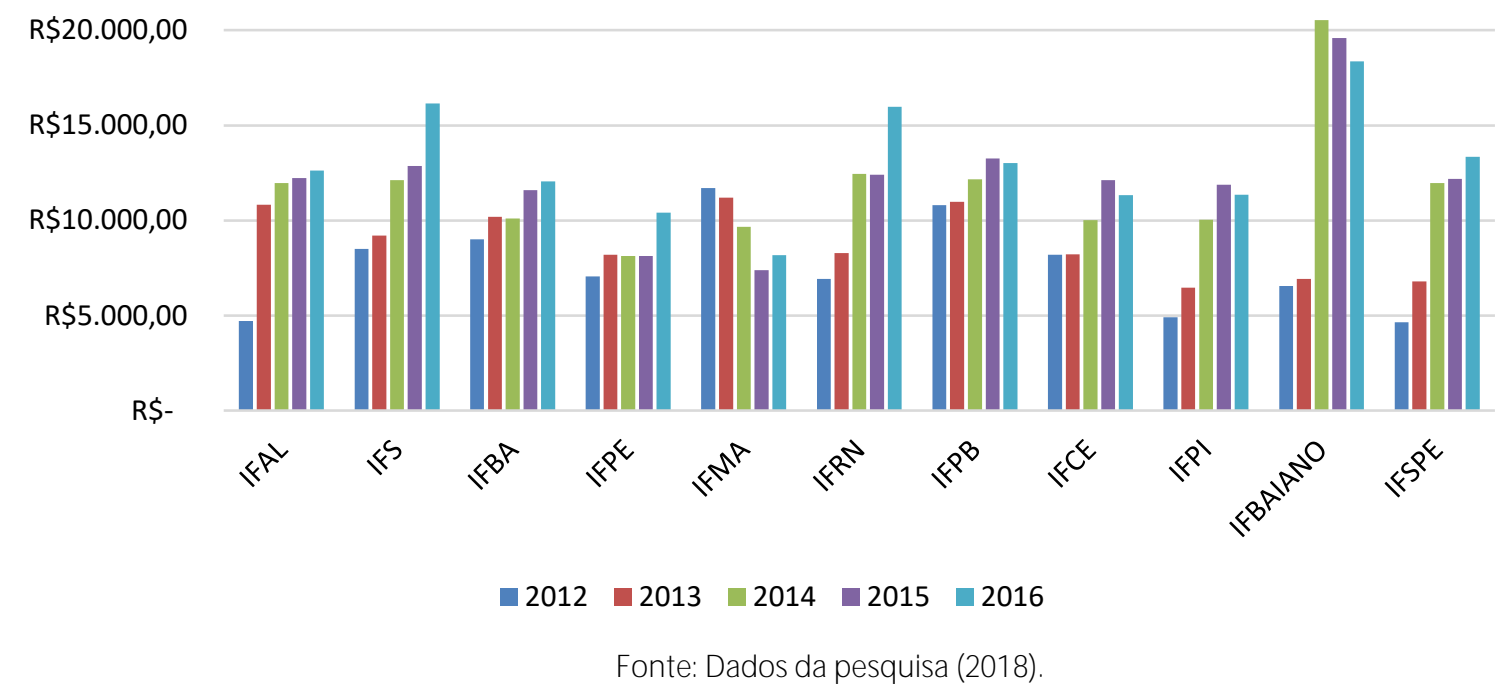

Assim, observando o Gráfico 1, é possível apreender que, além de ter sofrido diversas variações aumentativas ou diminutivas, fica claro que não há uma padronização dos valores gastos por aluno nas instituições. Enquanto o IFPE gastou, em média, no período, um valor de $\mathrm{R} \$ 8.382,29$ por aluno, o IF Baiano gastou em média R\$14.392,59 por aluno. Essa discrepância, contudo, não se reflete na taxa EAC. 
Gráfico 2 - Relação entre valores médios do GCA e a EAC média das instituições analisadas no período de 2012 a 2016

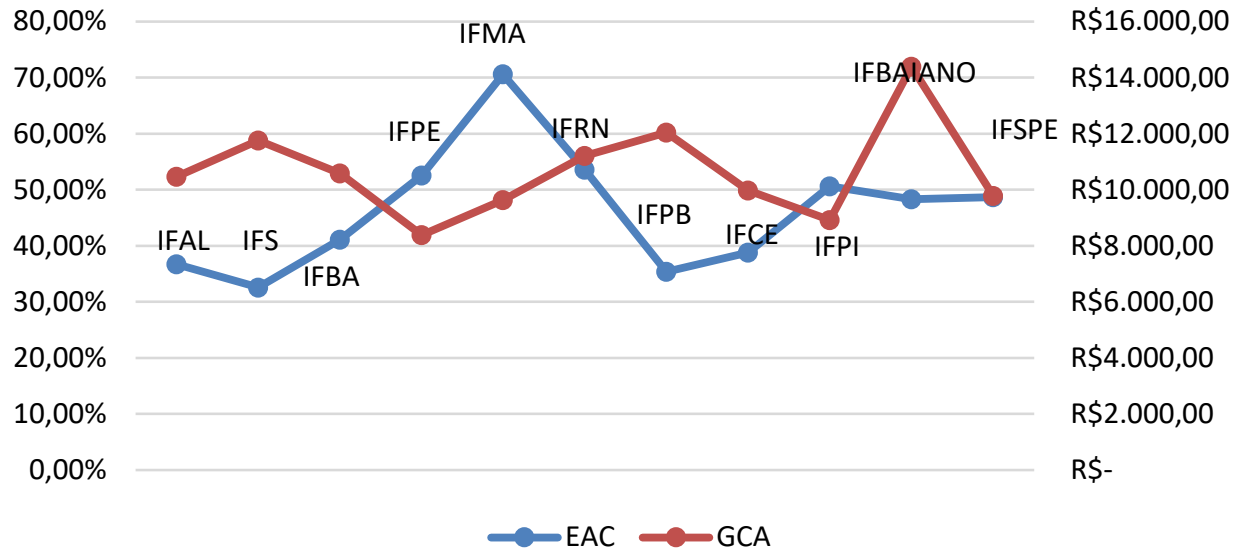

Fonte: Dados da pesquisa (2018).

Conforme gráfico 2, a média da EAC mais alta no período (IFMA) não corresponde à maior média de GCA, que é do IFBaiano. A média de EAC deste último, inclusive, não atinge, sequer, $50 \%$.

Estabelecendo relações entre todos os indicadores foi possível perceber que nem mesmo o índice médio de retenção do fluxo escolar interfere no EAC.

Como o EAC mede a capacidade de alcançar êxito entre os alunos que finalizam, uma possível relação seria de que, quanto maior fosse a retenção do fluxo escolar - que se refere aos alunos que trancaram o curso ou foram reprovados - menor deveria ser a EAC. Entretanto, analisando os dados disponíveis nos relatórios de gestão, isso não acontece e os índices comportam-se de maneira independente.

Gráfico 3 - Relação entre a média de retenção, EAC e RCM das instituições no período de 2012 a 2016

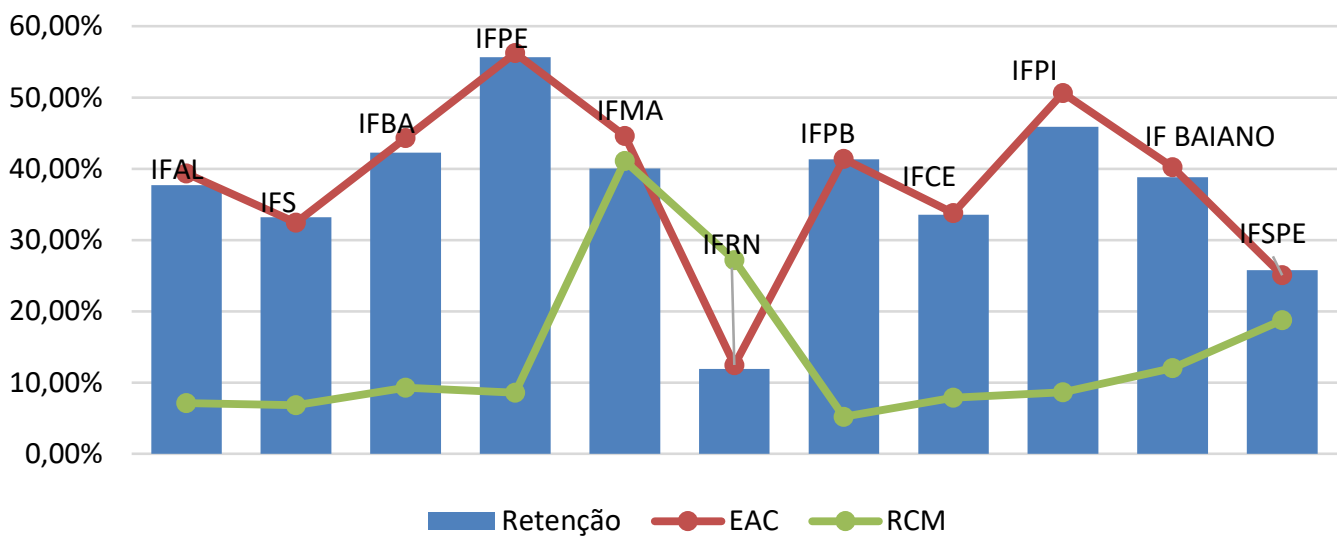

Fonte: Dados da pesquisa (2018).

De maneira geral, no período analisado, apesar dos investimentos e dedicação à expansão, há manutenção da EAC das instituições pesquisadas. Conforme os dados apresentados no gráfico 4, em 2014 houve um melhor desempenho da EAC, contudo, em 2015, houve uma involução, sendo a pior EAC média do período analisado. 
Gráfico 4 - Evolução do EAC por instituição no período compreendido entre 2012 e 2016

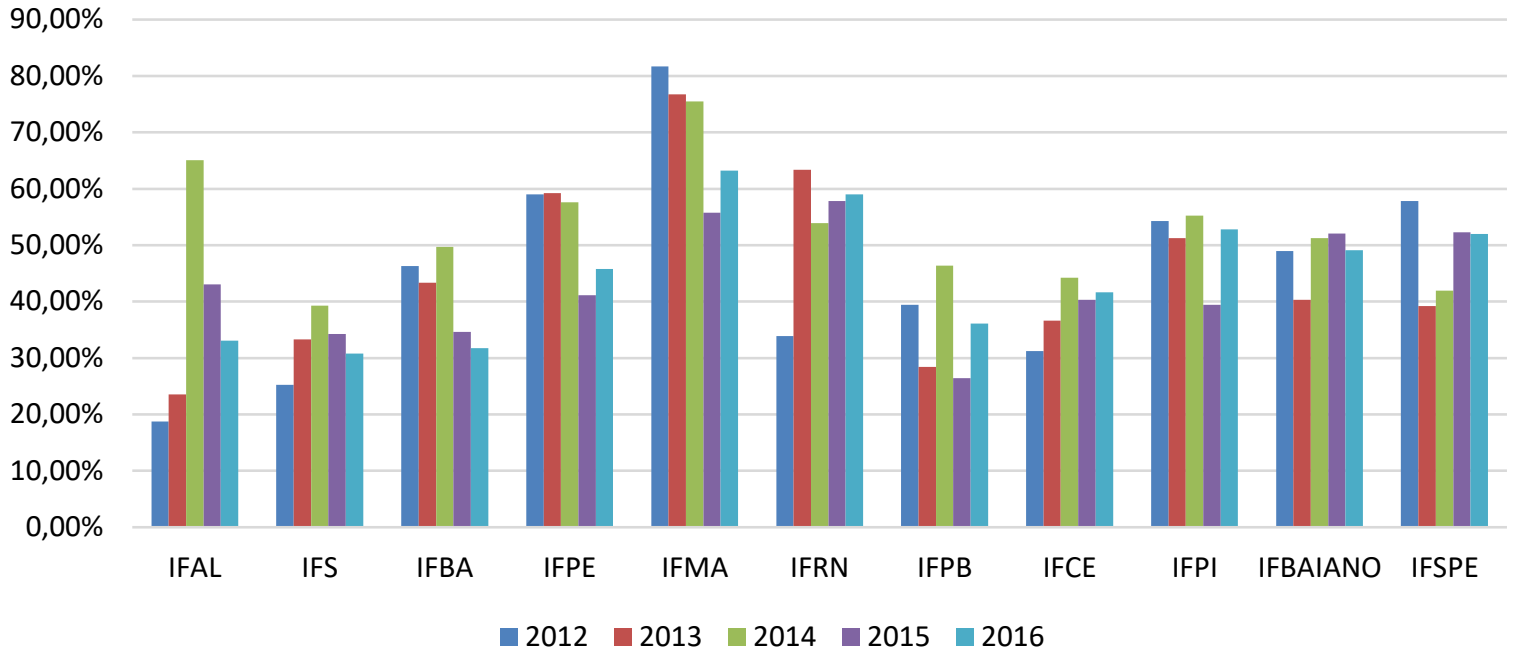

Fonte: Dados da pesquisa (2018).

Vale ainda ressaltar, que, embora, inicialmente não seja possível estabelecer relação direta entre os indicadores de gestão, como os relativos aos gastos com alunos, com investimentos, com pessoal e outros gastos e a EAC, cabe analisar a evolução desses indicadores em conjunto a outras informações e dados que não foram os estabelecidos por acórdão e, não são objeto desse estudo.

Assim, retomando o objetivo proposto pelo trabalho, que seria analisar a correlação entre o Indicador Eficiência Acadêmica de Concluintes (EAC) e os indicadores de gestão estabelecidos pelo Tribunal de Contas da União, chega-se à conclusão de que não há correlação entre a eficiência dos discentes das IFEs analisadas e os demais indicadores de gestão propostos pelo TCU. Uma possibilidade para esse resultado é que a Corte de Contas se preocupou em elaborar fórmulas para mensurar o desempenho institucional, entretanto, desprezou aspectos socioeconômicos e culturais dos discentes. E, conforme Silva et al. (2017, p. 6) "medir resultados não é tão simples quanto medir valores monetários".

A política pública de expansão das IFEs encontrou nessa primeira década diversos desafios históricos para estabelecer-se em determinadas regiões. A região Nordeste, analisada nesse artigo, é a que apresenta o maior índice de pobreza do país, onde $43,5 \%$ da população se enquadram nessa situação (IBGE, 2017). Ainda, segundo Síntese de Indicadores Sociais 2017 (IBGE, 2017), todas as grandes regiões do país experimentaram acréscimo no percentual dos jovens que não estudavam, nem estavam ocupados entre 2014 e 2016, mas apenas no Nordeste 0 aumento foi maior do que o observado nacionalmente. A cultura de tolerância ao jovem fora da escola para ocupar postos informais e sazonais de trabalho, como apontado em pesquisa do IBGE, tem o poder de interferir profundamente no resultado dos indicadores propostos pelo TCU.

As IFEs, com a possibilidade de levar excelência no ensino, pesquisa e extensão impactando essa região, cumpre o papel de política pública intersetorial estruturada para diminuir as desigualdades sociais por meio de uma educação desenvolvimentista. Entretanto, para que isso aconteça, os resultados precisam ser analisados de maneira mais realista, considerando os diversos aspectos que influenciam indicadores.

\section{CONCLUSÃo}

Essa pesquisa propôs analisar se existe relação entre o aumento de gastos do governo, após o estabelecimento da política pública de expansão do ensino público federal, nos Institutos Federais da Região Nordeste entre os anos de 2012 e 2016, que tem sua execução medida por indicadores de gestão estabelecidos no Acórdão no 2.267/2005 - TCU/Plenário e a eficiência acadêmica, medida por indicador indicado no mesmo documento. Para isso, sistematizou-se a evolução das políticas públicas voltadas para a educação profissional e tecnológica ao longo do tempo no Brasil evidenciando a importância das mesmas para a sociedade. 
Após essa análise, a partir de informações disponibilizadas nos relatórios de gestão das instituições, avaliou-se a eficiência dos discentes, medidas pela EAC relacionando-a com a gestão financeira da instituição, mensurada por indicadores do TCU. Os resultados demonstram que os indicadores não se relacionam entre si, ora apresentando-se como diretamente, ora como inversamente proporcionais. Uma das possíveis causas para esse fenômeno deve-se aos aspectos socioculturais desprezados no estabelecimento dos indicadores pelo TCU que não considerou, sequer, as particularidades regionais onde cada instituição está localizada e o público que atende.

Considerar os Institutos Federais de Educação, Ciência e Tecnologia como uma política pública exitosa em alcançar regiões do Brasil, que anteriormente não estavam no mapa da educação, vai além de analisar relações entre a conclusão dos alunos e os valores gastos para tal. Sem ousar minimizar a importância do acompanhamento dos resultados das instituições públicas a fim de aferir a sua eficiência e efetividade e, assim, exercer o acompanhamento e controle que são vitais no ciclo da política pública, cabe destacar que a EAC não pode ser a única medida direta do desempenho discente.

Especialmente após a expansão, a rede Federal tem alcançado resultados de destaque em diversos exames nacionais e internacionais, estando sempre entre as instituições melhor colocadas no ranking do Enem, e, superando, no Programme for International Student Assessment (Pisa) - Programa Internacional de Avaliação de Estudantes, as redes estadual e particular de ensino em Matemática, Leitura e Ciências (BRASIL, 2016), além do ótimo desempenho em olimpíadas de conhecimento e na pesquisa e iniciação científica.

Assim, destaque-se que este artigo analisou a eficiência acadêmica das instituições estabelecidas como amostra, apenas em relação a um grupo limitado de indicadores, os estabelecidos pelo TCU, por serem estes adotados por todas. A escolha do escopo, vale ressaltar, se deu pela escassez de produção científica que trate desse tema, bem como pela relevância em discutir se os recursos estão sendo empregados de maneira eficaz e se os indicadores adotados para acompanhamento dos mesmos, o fazem com fidedignidade, enquanto instrumento de avaliação de política pública.

Em tempo, sugere-se como tema de trabalho futuro, uma nova pesquisa cujo foco seja a abordagem de aspectos socioeconômicos e culturais que impactam no resultado da EAC.

\section{REFERÊNCIAS}

ARAÚJ O, Marlene de; GAZZOLA, Rosaura. Políticas públicas: prestação de contas dos atores. Revista de Política Agrícola, Brasília, v. 26, n. 1, p. 25-37, 2017.

BRASIL. Constituição Federal de 1988. Promulgada em 5 de outubro de 1988. Disponível em: http://www.planalto.gov.br/ccivil_03/constituicao/constituicaocompilado.htm. Acesso em: 15 jan. 2018

Lei 11.892 de 29 de dezembro de 2008. Institui a Rede Federal de Educação Profissional, Científica e Tecnológica, cria os Institutos Federais de Educação, Ciência e Tecnologia, e dá outras providências. Disponível em: http://www.planalto.gov.br/ccivil_03/_ato2007-2010/2008/lei//11892.htm. Acesso em: 15 jan. 2018

Ministério da Educação. Brasil no PISA 2015: análises e reflexões sobre o desempenho dos estudantes brasileiros. OCDE - Organização para a Cooperação e Desenvolvimento Econômico — São Paulo: Fundação Santillana, 2016. Disponível em:

http://download.inep.gov.br/acoes_internacionais/pisa/resultados/2015/pisa2015_completo_final_baixa.pdf . Acesso em: 15 jan. 2018.

Ministério da Educação. Secretaria de Educação Profissional e Tecnológica. Manual para produção e análise de indicadores da rede federal de EPCT. Brasília, DF: MEC, 2014. Disponível em: http://sitesistec.mec.gov.br/images/arquivos/pdf/manual_indicadores_gestao_exercicio2014.pdf. Acesso em: 15 jan. 2018

Ministério da Educação. Políticas Públicas para Educação Profissional e Tecnológica. Brasília, 2004. Disponível em: http://portal.mec.gov.br/setec/arquivos/pdf/p_publicas.pdf. Acesso em: 09 jan. 2018. 
Ministério da Educação. Um Novo Modelo Em Educação Profissional E Tecnológica. Concepção e Diretrizes. Brasília, 2010. Disponível em:

http://portal.mec.gov.br/index.php?option=com_docman\&view=download\&alias=6691-ifconcepcaoediretrizes\&category_slug=setembro-2010-pdf\&ltemid=3019. Acesso em 17 dez. 2017.

Ministério do Planejamento, Orçamento e Gestão. Secretaria de Planejamento e Investimentos Estratégicos - SPI. Indicadores de programas: Guia Metodológico / Ministério do Planejamento, Orçamento e Gestão, Secretaria de Planejamento e Investimentos Estratégicos - Brasília: MP, 2010. 128 p.: il. color.

Tribunal de Contas da União - TCU. ACÓRDÃO № 2.267/2005 - TCU - Plenário. Relatório de Auditoria Operacional e de Legalidade na Secretaria de Educação Média e Tecnológica do Ministério da Educação - Setec/MEC. Ata no 49/2005 - Plenário. Brasília, DF, 13 de dezembro de 2005. Disponível em: http://www.tcu.gov.br/Consultas/J uris/Docs/judoc/Acord/.../TC-004-550-2004-0.do. Acesso em 23 dez. 2017.

Tribunal de Contas da União - TCU. ACÓRDÃO № 2.508/2011 - TCU - Primeira Câmara. Tomada de Contas. Ata no 13/2011 - Primeira Câmara. Brasília, DF, 26 de abril de 2011. Disponível em:

https://contas.tcu.gov.br/pesquisal urisprudencia/\#/detalhamento/11/\%252a/NUMACORDA0\%253A2508\%2 520ANOACORDAO\%253A2011/DTRELEVANCIA\%2520desc\%252C\%2520NUMACORDAOINT\%2520desc/false /2/false. Acesso em 23 dez. 2017.

BUENO, Alexandre; TORKOMIAN, Ana Lúcia Vitale. Índices de licenciamento e de comercialização de tecnologias para núcleos de inovação tecnológica baseados em boas práticas internacionais. Encontros Bibli: revista eletrônica de biblioteconomia e ciência da informação, Florianópolis, v. 23, n. 51, p. 95-107, jan. 2018. ISSN 1518-2924. Disponível em: https://periodicos.ufsc.br/index.php/eb/article/view/15182924.2018v23n51p95/35513. Acesso em: 02 maio 2018.

COELHO, Michelle Queiroz. Indicadores de performance para projetos sociais: a perspectiva dos stakeholders. Revista Alcance, Biguaçu, SC, v. 11, n. 3, p. 423-444, set./dez. 2009.

GOMES, F. P.; ARAÚJ O, R. M. de. Pesquisa qualiquantitativa em administração: uma visão holística do objeto de estudo. In: SEMINÁRIOS EM ADMINISTRAÇÃO (SEMEAD), 8., 2005, São Paulo. Anais [...]. Disponível em: http://sistema.semead.com.br/8semead/resultado/trabalhosPDF/152.pdf. Acesso em: 10 jan. 2018.

HÖFLING, Eloisa de Matos. Estado e políticas (públicas) sociais. Cadernos Cedes, Campinas, SP, v. 21, n. 55, p. 30-41, 2001.

IBGE. Síntese de indicadores sociais: uma análise das condições de vida da população brasileira: 2017 /, Coordenação de População e Indicadores Sociais. - Rio de J aneiro: IBGE, 2017 147p. Disponível em: https://biblioteca.ibge.gov.br/visualizacao/livros/liv101459.pdf. Acesso em 15 jan. 2018.

KLOOT, Louise; MARTIN, J ohn. Strategic performance management: A balanced approach to performance management issues in local government. Management Accounting Research, v. 11, n. 2, p. 231-251, 2000. Disponível em: http://www.sciencedirect.com/science/article/pii/S1044500500901306. Acesso em: 10 jan.2018.

PALADINO, Carolina de Freitas. Políticas públicas: considerações gerais e possibilidade de controle judicial. A\&C-Revista de Direito Administrativo \& Constitucional, Curitiba, v. 8, n. 32, p. 219-240, 2008.

PETRI, Sérgio M. Modelo para apoiar a avaliação das abordagens de gestão de desempenho e sugerir aperfeiçoamentos: sob a ótica construtivista. 2005.236f.

Tese (Doutorado em Engenharia de Produção) - Programa de Pós-Graduação em Engenharia de Produção da Universidade Federal de Santa Catarina, Florianópolis, Santa Catarina, Brasil, 2005.

RESENDE, Viviane de Melo. Análise interdiscursiva de políticas públicas: Reflexão epistemológica. Ambitos: Revista Internacional de Comunicación, Sevilla, Espanha, n. 39, p. 6, 2017. 
SILVA, Polyana Tenório de Freitas et al. Indicadores de gestão do ensino superior e sua correlação e retenção: uma análise da taxa de sucesso na graduação em seis instituições federais de ensino entre 2006 e 2015. In: SIMPÓSIO INTERNACIONAL DE GESTÃO DE PROJ ETOS, INOVAÇÃO E SUSTENTABILIDADE (SINGEP), VI, São Paulo, SP, 2017. Anais [...]. Disponível em: https://singep.org.br/6singep/resultado/506.pdf. Acesso em: 12 jan. 2018.

SOLIGO, Valdecir. Indicadores: conceito e complexidade do mensurar em estudos de fenômenos sociais. Estudos em Avaliação Educacional, São Paulo, v. 23, n. 52, p. 12-25, 2012.

SOUZA, Celina. Políticas públicas: uma revisão da literatura. Sociologias, Porto Alegre, v. 8, n. 16, jul./dez., p. $20-45,2006$.

SOUZA, Francisco das Chagas Silva et al. Institutos Federais: expansão, perspectivas e desafios. Revista Eletrônica Científica Ensino Interdisciplinar, Natal, v. 2, n. 5, p. 17-26, 2016. Disponível em: http://periodicos.uern.br/index.php/RECEl/article/viewFile/1949/1048. Acesso em: 17 dez. 2017. 